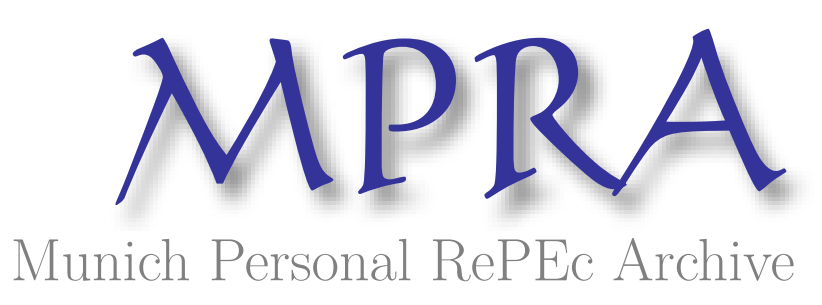

\title{
Patenting in the Shadow of Independent Discoveries by Rivals
}

\author{
Zhang, Tianle
}

2009

Online at https://mpra.ub.uni-muenchen.de/32917/

MPRA Paper No. 32917, posted 22 Aug 2011 10:10 UTC 


\title{
Patenting in the Shadow of Independent Discoveries by Rivals*
}

\author{
Tianle Zhang \\ The Hong Kong Polytechnic University, Hong Kong \\ Revised May 2011
}

\begin{abstract}
This paper studies the decision of whether to apply for a patent in a dynamic model in which firms innovate stochastically and independently. In the model, a firm can choose between patenting and maintaining secrecy to protect a successful innovation. I consider a legal environment characterized by imperfect patent protection and no prior user rights. Thus, patenting grants probabilistic protection, and secrecy is effectively maintained until rivals innovate. I show that (1) firms that innovate early are more inclined to choose secrecy, whereas firms that innovate late have a stronger tendency to patent; (2) the incentives to patent increase with the innovation arrival rate; and (3) an increase in the number of firms may cause patenting to occur earlier or later, depending on the strength of patent protection. The socially optimal level of patent protection, which balances the trade-off between the provision of patenting incentives and the avoidance of deadweight loss caused by a monopoly, is lower with a higher innovation arrival rate or a larger number of firms.
\end{abstract}

Key words: Patenting decisions; Patents; Secrecy; Independent discoveries.

JEL Classification: O31, O34

*I thank Yongmin Chen for his advice and encouragement throughout the course of this research. I also thank the Co-Editor, two anonymous referees, Martin Byford, Yuk-fai Fong, Byung-Cheol Kim, Jennifer Lamping, Ben Li, Keith Maskus, Anna Rubinchik, Scott Savage, Hâle Utar, Xinpeng $\mathrm{Xu}$, Lei Yang and the participants of the 7th International Industrial Organization Conference, European Economic Review Talented Economists Clinic 2, and seminars at the Hong Kong University of Science and Technology and the Southwestern University of Finance and Economics for their helpful comments. All errors are my own. 


\section{Introduction}

An important strategic decision for a firm is how to protect innovations. The firm can apply for patent protection or keep its innovation for secret use. Evidence indicates that firms often make heterogeneous choices about whether to patent their innovations. In fact, only a small proportion of innovations are patented (Scherer, 1965; Pakes and Griliches, 1980; Mansfield, 1986), and secrecy is increasingly viewed as an important strategy for appropriating innovations (Levin et al., 1987; Cohen et al., 2000). A question that naturally arises is why some firms choose to apply for patents whereas others adopt secrecy to protect their innovations. Moreover, given firms' strategic decisions concerning whether to patent, what is the socially optimal level of patent protection?

This paper attempts to address these questions. The analysis presented herein is motivated by several observed features concerning innovations and patenting. First, in many situations, multiple firms are capable of independently devising similar or even identical innovations. As Varian et al. (2005) and Shapiro (2007) discuss, such duplication can occur because firms often share common knowledge bases or find their research paths restricted by universal standards. Second, patent protection is probabilistic. Many patent applications are not approved, ${ }^{1}$ and as Choi (1998) and Lemley and Shapiro (2005) emphasize, even issued patents can be ruled invalid through litigation. ${ }^{2}$ Given the requirement for full disclosure of innovation information during the patenting process, the information that is revealed may be utilized to the benefit of rival firms under conditions of imperfect patent protection. Third, a firm that keeps an innovation secret runs the risk of allowing another firm to obtain a patent for that innovation. Under current U.S. patent laws, a later inventor is permitted to obtain a patent for an invention that was abandoned, suppressed or concealed by previous inventors (Merges and Duffy, 2007). In addition, U.S. patent laws grant no prior user rights, ${ }^{3}$ which means that a later inventor has the right to exclude previous inventors that rely on secrecy. ${ }^{4}$

To capture these features, this paper develops a dynamic model of innovation in which multiple firms stochastically and sequentially discover a technology that is critical to a cost-

\footnotetext{
${ }^{1}$ Of the 485,312 applications received in 2008, only 185,224 (less than 40\%) patents were granted. Data source: U.S. Patent Statistics Chart. http://www.uspto.gov/go/taf/us_stat.htm.

${ }^{2}$ Allison and Lemley (1998) report that out of the 300 cases of final validity decisions in their data set, patents were declared invalid in 138 cases.

${ }^{3}$ With exceptions for business methods.

${ }^{4}$ As Denicolò and Franzoni (2004a) report in their discussion of Gore v. Garlock (721 F.2d 1540, 1983), Garlock Inc. had discovered a process for creating a tape of unsintered polytetrafluorethylene filament, but decided to keep it secret. However, the process was later rediscovered by W.L. Gore \& Associates, Inc., which succeeded in patenting it. In another case discussed in Marshall (1991), both New England Biolabs and Bethesda Research Labs produced modified T7 DNA polymerase and offered it for sale, but neither applied for a patent. The patent for it was later granted to Harvard researchers who threatened the two labs with a lawsuit for using it.
} 
reduction process or to the development of a new product. The firms that have discovered the technology are referred to as innovators. When a discovery occurs, the innovator decides whether to seek patent protection or rely on secrecy. Patent protection is imperfect in that it is effective with only some degree of probability. Moreover, the model assumes a legal environment with no prior user rights (e.g. the U.S. patent system). Within this legal environment, a later innovator may be entitled to the exclusive use of the technology if previous innovators rely on secrecy protection.

Taking into account the uncertainty inherent in patent protection and the threat of independent discoveries by rivals, an innovator's choice between patenting and secrecy becomes less than clear. In particular, by applying for a patent, an innovator that initially seeks to exclude its competitors, may provide help to them by disclosing innovation information if the patent protection is ineffective. Cohen et al. (2000) report such information disclosure to be one of the main reasons for innovators not to seek patent protection. By adopting a secrecy strategy, an innovator with the intention to gain an edge over its rivals may fail to do so if these rivals are able to discover the technology independently within a short period of time. As a matter of fact, blocking rivals from obtaining patents on related innovations is often a motive for firms to patent.

In Section 3, I describe the equilibrium of the model and show how innovators' patenting decisions depend on the timing of discovery (whether the discovery occurs early or late), the nature of an innovation (the innovation arrival rate) and the degree of market competition (the number of firms in the market). Early innovators are more inclined to choose secrecy, whereas late innovators have a stronger tendency to opt for patents. In other words, patenting incentives increase as more firms innovate. Consequently, given a certain level of patent protection, in equilibrium, early innovators adopt secrecy and only a sufficiently late innovator chooses to patent. A simple condition is provided to identify the critical innovator that chooses to patent. Moreover, I find that firms' incentives to patent are greater if the innovation arrival rate is higher. This result helps explain why firms in hi-tech industries, which feature by high innovation arrival rates, may choose patenting despite weak industry patent protection. Finally, I show that an increase in the number of firms may cause patenting to occur earlier or later, depending on the strength of patent protection, which suggests that greater competition does not necessarily promote innovation information disclosure.

The analysis in this paper sheds light on the important policy issue of the socially optimal level of patent protection. In the model, the arrivals of innovations are assumed to be exogenously determined. Thus, the issue of ex-ante innovation incentives is not a concern. A patent is viewed as a contract or agreement between society and the innovator in the sense 
that certain monopoly power is granted in exchange for innovation information disclosure. ${ }^{5} \mathrm{~A}$ social planner faces the following trade-off in choosing the optimal level of patent protection. For a weak patent protection, early innovators are more likely to adopt secrecy. Thus, the society will experience markets in which firms have strong market power until the time that more firms innovate. To speed up the disclosure of innovation information, stronger patent protection is necessary, although it is associated with a greater chance of a monopoly market. I derive the socially optimal level of patent protection and show it to be lower with a higher innovation arrival rate or a larger number of firms.

Section 6 considers a simple model with an endogenous innovation arrival rate. I employ the framework of Loury (1979) and assume that firms incur an up-front R\&D investment in the first stage that generates a steady flow of innovation arrivals over time. In the second stage, each firm decides whether to patent when its innovation occurs. I argue that the results from the model with the exogenous innovation arrival rate remain valid in the extended model. Moreover, I explore how the strength of patent protection affects the incentive to innovate. In this model setting, there is a possibility that an increase in patent protection can impede R\&D investment.

A small body of literature has studied firms' patenting decisions under imperfect patent protection. However, these studies typically assume away the possibility that firms compete to patent identical or similar innovations (Gallini, 1992; Horstmann, MacDonald and Slivinski, 1985; Anton and Yao, 2004). Anton and Yao (2004), for example, present a model in which a firm with private information about the profitability of an innovation chooses between patenting and secrecy and also decides on the amount of innovation information to disclose. In their model, patenting signals low innovation profitability to a potential imitator. The model in this paper involves no asymmetric information issues. Instead, by developing a model with perfect information, I explore firms' patenting decisions under conditions of imperfect patent protection and the possibility of multiple independent discoveries.

Kultti, Takalo and Toikka $(2006,2007)$ consider a situation in which multiple firms that innovate independently choose between patenting and secrecy. However, there are notable differences between this paper and theirs. In their models, firms innovate simultaneously and decide whether to patent based on the level of patent and secrecy protection. This paper complements theirs in that it models independent discoveries that occur stochastically and sequentially. In the present model, an early innovator decides whether to patent by taking into account the strategies of later innovators.

This paper is also related to the literature on multiple patents and the defense of inde-

\footnotetext{
${ }^{5}$ See Denicolò and Franzoni (2004b) for discussions on the distinction between "reward theory" and "contract theory" of patents.
} 
pendent inventions (La Manna, MacLeod and de Meza, 1989; Shapiro, 2006; Denicolò and Franzoni, 2004a, 2010). In this literature, the key issue is the optimal allocation of prizes or the mechanisms by which these prizes are awarded in an innovation race. This paper has a different focus, examining innovators' choice between patenting and secrecy decisions in a particular legal environment in which the patent system grants no prior user rights.

Choi (1990) and Erkal (2005) investigate decisions to patent from another interesting and important angle. In a framework of cumulative innovation, they examine two options for an innovator: to patent (and commercialize) the basic version of a product or to keep it secret and work on developing an improved version. They assume perfect patent protection and emphasize the competition among firms in the development of vertically differentiated products. This paper considers the situation of identical innovations (or horizontally similar innovations) and probabilistic patent protection.

The remainder of the paper is organized as follows. Section 2 describes the model. Section 3 conducts equilibrium analysis. Section 4 performs comparative statics. Section 5 derives the socially optimal level of patent protection. Section 6 considers a simple model with an endogenous innovation arrival rate. Section 7 concludes the paper. All proofs are relegated to the Appendix.

\section{The Model}

Consider an industry with a fixed number, $n$, of ex-ante identical firms. These firms are about to discover a technology that is crucial to a cost-reduction process or to the development of a new product. ${ }^{6}$ The discovery process for each firm is independent and identical, and is determined by a Poisson process with an exogenous arrival rate, $\lambda .{ }^{7}$ There are three reasons to focus on an exogenous innovation process. First, in a number of situations, a creative idea is essential for an innovation to occur. Once the idea arrives, it can be turned into an innovation at negligible cost. In addition, ideas are likely to arrive in a stochastic fashion. Thus, the model fits certain innovation environments. ${ }^{8}$ Second, the primary objective of this paper is to understand how firms make patenting decisions. Abstracting from investment choices allows us to disentangle the trade-offs in the patenting decision in a more transparent way. Third, the assumption of an exogenous innovation process serves the purpose of separating patents' function to induce innovation information disclosure from

\footnotetext{
${ }^{6}$ For convenience, only one technology is considered. Alternatively, the firms could be about to discover different but similar technologies that are likely to be covered by one patent.

${ }^{7}$ The Poisson process has been extensively used in the literature on the economics of innovation. See Reinganum (1989) for a survey. Some researchers call $\lambda$ the hit rate or hazard rate.

${ }^{8}$ See Scotchmer (2004) and Erkal and Scotchmer (2009) for discussions on models of innovation "ideas."
} 
that to provide ex-ante innovation incentives.

When a technology discovery occurs, the innovator decides whether to patent that technology or to keep it secret. To capture the fact that patent protection is probabilistic, in line with Kultti, Takalo and Toikka (2007), I assume the following: with probability $\alpha$, an innovator who applies for patent protection is granted an infinitely lived, perfectly effective property right on the technology; with probability $1-\alpha$, patent protection is ineffective, the technology becomes public, and other firms can access it. To simplify the analysis, the costs associated with patenting are normalized to zero. ${ }^{9}$ By adopting secrecy, an innovator can use the technology until another innovator successfully obtains effective patent protection. To focus on the effect of multiple innovation discoveries, it is assumed that information on the technology does not leak out if it is kept secret. ${ }^{10}$

Firms earn profits in an output market. Rather than relying on a specific form of competition, I assume a general profit function that depends only on the number of producing firms. In particular, let $\pi_{i}$ be the instantaneous profit for each firm when $i$ firms are producing in the product market. It is assumed that $\pi_{i}$ is strictly decreasing and convex in $i^{11}$ Three possible scenarios may appear, each of which determines the number of producing firms and their profits: (1) if patent protection is effective, then the patentee earns $\pi_{1}$ and the other firms earn no profits; (2) if patent protection is ineffective, then all firms produce and each earns $\pi_{n}$; and (3) if $i$ firms discover the technology and all of them opt for secrecy, then each of the $i$ firms earns $\pi_{i}$, and the others earn no profits.

Issues of asymmetric information are not considered here, and whether a firm has discovered the technology is common knowledge. The timing of the model is shown in Figure 1. As firms are ex-ante identical, without loss of generality, they are indexed by the order of discoveries. Let innovator $j$ (or firm $j$ ) be the $j$ th firm that discovers the technology, where $j \in N$ and $N=\{1,2, \cdots, n\}$. Time is continuous. Period $j$ begins when innovator $j$ discovers the technology and ends when innovator $j+1$ discovers it. At the beginning of period $j$, innovator $j$ decides whether to apply for patent protection if no patent has previously been granted. If innovator $j$ chooses to apply for a patent, then nature determines whether the patent protection is effective. Alternatively, innovator $j$ can keep the technology secret. In this case, the model moves on to period $j+1$, in which innovator $j+1$ discovers the technology and decides whether to apply for a patent.

\footnotetext{
${ }^{9}$ The model can easily incorporate the case of a positive patenting cost, $\tau$, by scaling down the profit associated with the patenting strategy by $\tau$.

${ }^{10}$ Thus, a firm can access the technology information only if it discovers the technology itself or if patent protection is ineffective.

${ }^{11} \mathrm{~A}$ simple example is Cournot competition with linear market demand and a constant marginal production cost.
} 


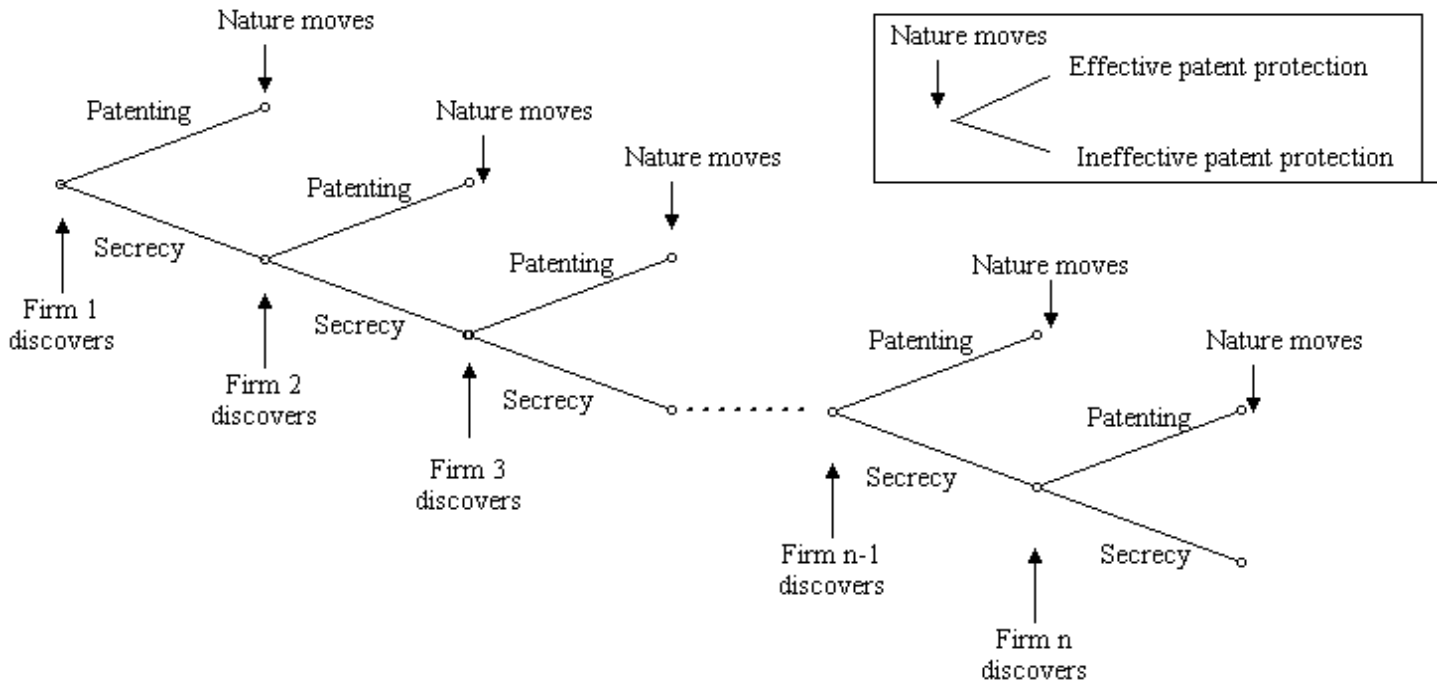

Figure 1: Timing of the game

The equilibrium concept in this model is a subgame perfect Nash equilibrium (SPNE). Given that no previous patent has been granted, an innovator, taking into account the optimal strategies of subsequent innovators, chooses between patenting and secrecy to maximize its expected profit. In equilibrium, the innovators' patenting decisions are mapped from $N$ to $\{P, S\}$, where $P$ and $S$ stand for patenting and secrecy, respectively.

\section{Equilibrium Analysis}

In deciding whether to patent, a firm compares the expected profits from the patenting and secrecy strategies. As innovator $j$ makes its patenting decision at the beginning of period $j$, the future profit streams should be discounted as a present value.

I first consider the expected profit for innovator $j$ if it chooses to apply for patent protection conditional upon all previous innovators adopting secrecy. With probability $\alpha$, innovator $j$ is awarded with effective patent protection, thereby reaping a monopoly profit of $\pi_{1}$. With probability $1-\alpha$, patent protection is ineffective, and innovator $j$ earns a profit equal to $\pi_{n}$. Hence, the expected profit for innovator $j$ if it patents is

$$
\begin{aligned}
\Pi_{p} & =\int_{0}^{\infty}\left[\alpha \pi_{1}+(1-\alpha) \pi_{n}\right] e^{-r t} d t \\
& =\frac{1}{r}\left[\alpha \pi_{1}+(1-\alpha) \pi_{n}\right] .
\end{aligned}
$$


Note that $\Pi_{p}$ is invariant with the rank of discoveries and does not depend on the patenting strategies of subsequent innovators. The reason is that the uncertainty over patent protection is fully removed once a firm chooses to patent.

If innovator $j$ adopts secrecy, then its expected profit depends on the strategies of subsequent innovators. Let $\Pi_{s}(j \mid h)(h>j)$ denote the expected profit for innovator $j$ if it adopts secrecy, where $h$ is the first innovator after $j$ that chooses to patent. Thus, $\Pi_{s}(j)=\Pi_{s}(j \mid j+1)$ is the expected profit if innovator $j$ opts for secrecy, given that the next innovator chooses to patent. $\Pi_{s}(j)$ originates from two sources. One is the expected profit associated with secrecy protection in period $j$, and the other is the expected profit from period $j+1$ and subsequent periods. Given that the next innovator chooses to patent, innovator $j$ earns profits from period $j+1$ and subsequent periods only if patent protection is ineffective, which occurs with probability $1-\alpha$. It is straightforward to show that

$$
\begin{aligned}
\Pi_{s}(j) & =\int_{0}^{\infty} e^{-\lambda(n-j) t}\left[\pi_{j}+\lambda(n-j)(1-\alpha) \int_{t}^{\infty} \pi_{n} e^{-r s} d s\right] e^{-r t} d t \\
& =\frac{\pi_{j}+\lambda(n-j)(1-\alpha) \frac{\pi_{n}}{r}}{r+\lambda(n-j)} \\
& =[1-x(j)] \frac{\pi_{j}}{r}+(1-\alpha) x(j) \frac{\pi_{n}}{r},
\end{aligned}
$$

where

$$
x(j)=\frac{\lambda(n-j)}{r+\lambda(n-j)},
$$

which can be viewed as the discounting adjusted probability that the $j+1$ th innovator succeeds. $^{12}$

$\Pi_{s}(j)$ is rewritten as

$$
\Pi_{s}(j)=\frac{\pi_{j}}{r} \cdot \frac{r+\left[(1-\alpha) \frac{\pi_{n}}{\pi_{j}}\right] \lambda(n-j)}{r+\lambda(n-j)}
$$

As $\pi_{j}$ decreases with $j$ and $(1-\alpha) \frac{\pi_{n}}{\pi_{j}}<1$, we immediately have the following lemma.

Lemma $1 \Pi_{s}(j)$ strictly decreases with $j$.

Now, consider innovator $j$ 's patenting decision if the next innovator chooses to patent. To avoid mixed strategies, I assume that a firm chooses to adopt secrecy if both patenting and secrecy strategies yield the same expected profit. Clearly, innovator $j$ chooses to patent if

$$
\Pi_{p}>\Pi_{s}(j)
$$

\footnotetext{
${ }^{12}$ I thank a referee for pointing out this mathematical arrangement and its economic interpretation.
} 
Define

$$
\alpha_{j}=\frac{\pi_{j}-\pi_{n}}{\frac{\pi_{1}}{1-x(j)}-\pi_{n}} \quad \text { for } \quad j=1, \ldots, n .
$$

By (1) and (2), (5) becomes

$$
\alpha>\alpha_{j}
$$

Thus, $\alpha_{j}$ can be interpreted as the incentive for innovator $j$ to patent if the next innovator also chooses to patent. A smaller $\alpha_{j}$ implies a greater incentive to patent.

By implicit differentiation,

$$
\frac{\partial \alpha_{j}}{\partial j}=\frac{\partial \Pi_{s}(j) / \partial j}{\partial \Pi_{p} / \partial \alpha_{j}-\partial \Pi_{s}(j) / \partial \alpha_{j}}<0
$$

noting that $\partial \Pi_{p} / \partial \alpha_{j}>0$ by $(1), \partial \Pi_{s}(j) / \partial \alpha_{j}<0$ by $(2)$, and $\partial \Pi_{s}(j) / \partial j<0$ by Lemma 1 . Thus, conditional on the next innovator choosing to patent, a later innovator has a greater incentive to patent.

Next, I turn to the case in which the optimal strategy for innovator $j+1$ is to adopt secrecy.

Lemma 2 If choosing secrecy over patenting is optimal for innovator $j+1$, then the same strategy has to be optimal for innovator $j$.

The key to understanding this result is to realize that innovator $j$ earns greater profit than innovator $j+1$ when both adopt secrecy, regardless of the strategies of subsequent innovators. Moreover, both innovators receive the same profit from patenting. Therefore, if innovator $j+1$ finds it optimal to choose secrecy over patenting, then innovator $j$ should also find the same strategy to be optimal.

Lemma 2 allows us to focus on analysis that is on the equilibrium path. If it is optimal for innovator $j$ to choose to patent, then innovator $j+1$ will choose to patent if innovator $j$ has sub-optimally opted for secrecy. One immediate result that follows from Lemma 2 is that if innovator $j+1$ optimally chooses secrecy, then all previous innovators will also find it optimal to choose secrecy in equilibrium. I now describe the equilibrium of the model.

Proposition 1 Let $\alpha_{0}=1$. Given the level of patent protection $\alpha$, there exists a unique $m \in N$ such that $\alpha_{m}<\alpha \leq \alpha_{m-1}$. In equilibrium, innovator $m$ chooses to patent, whereas previous innovators (if any) adopt secrecy.

Depending on the strength of patent protection, the innovation arrival rate, the number of firms and the timing of discoveries, firms may choose different means to protect their innovations. Two scenarios may occur in equilibrium. First, the first innovator chooses to 
patent. Second, firms that innovate early opt for secrecy, whereas only a sufficiently late innovator chooses to patent.

The following example illustrates Proposition 1.

Example 1 Let $n=3, \lambda=0.1$, and $r=0.2$. Moreover, assume linear market demand, $P=a-b Q$, and constant marginal cost, c. By (6), $\alpha_{1}=0.43, \alpha_{2}=0.16$, and $\alpha_{3}=0$. Therefore, if $\alpha>\alpha_{1}$, then in equilibrium, innovator 1 patents. If $\alpha_{1} \geq \alpha>\alpha_{2}$, then in equilibrium, innovator 1 adopts secrecy, and innovator 2 patents. If $\alpha_{2} \geq \alpha>\alpha_{3}$, then in equilibrium, innovators 1 and 2 adopt secrecy, and innovator 3 patents.

This section concludes by showing how innovators' expected profits depend on the order of discoveries.

Proposition 2 Innovators' expected profits decrease with the order of discoveries.

\section{Comparative Statics}

This section examines how changes in the strength of patent protection, the innovation arrival rate and the number of firms affect the incentives to patent and the timing of patenting. Proposition 1 has shown that there is a unique $m=m(\alpha, \lambda, n)$, such that innovator $m$ patents and previous innovators (if any) opt for secrecy. Define $\rho(\alpha, \lambda, n)$ as the proportion of firms that adopt secrecy:

$$
\rho(\alpha, \lambda, n)=\frac{m(\alpha, \lambda, n)-1}{n} .
$$

As the industry innovation arrival rate during period $i$ is $(n-i) \lambda$, the expected length of period $i$ is

$$
T_{i}(n, \lambda)=\frac{1}{(n-i) \lambda}
$$

Define $T(\alpha, \lambda, n)$ as the expected time that patenting occurs:

$$
T(\alpha, \lambda, n)=\sum_{i=1}^{m(\alpha, \lambda, n)-1} T_{i}(n, \lambda) .
$$

I first show the effect of a change in the level of patent protection $\alpha$.

Proposition $3 m(\alpha, \lambda, n), \rho(\alpha, \lambda, n)$ and $T(\alpha, \lambda, n)$ decrease with $\alpha$.

The intuition is straightforward. Strengthening patent protection directly increases the profit that arises from patenting. At the same time, it reduces that arising from secrecy 
because subsequent innovators have a greater chance of obtaining effective patent protection. Therefore, a higher $\alpha$ encourages firms to choose patenting and thus advances the timing of patenting.

I next examine the effect of a change in the innovation arrival rate $\lambda$.

Proposition $4 m(\alpha, \lambda, n), \rho(\alpha, \lambda, n)$ and $T(\alpha, \lambda, n)$ decrease with $\lambda$.

An increase in the innovation arrival rate has no effect on the profit that stems from patenting. However, it does shorten the duration of the period in which an innovator enjoys the profit that stems from secrecy because discoveries by rival firms arrive more quickly. Thus, the profit from secrecy decreases with $\lambda$. Consequently, innovators have greater incentives to patent, and patenting occurs earlier.

The finding that firms prefer patenting under a larger $\lambda$ may help explain why firms in hitech industries find patenting attractive despite relatively weak industry patent protection. Independent discoveries are likely to occur frequently in these industries. Hence, expecting that their rivals will soon discover the technology, firms find secrecy protection of little value and choose to patent even if patent protection is weak.

It is easy to show that given a certain patent protection level, there always exists a sufficiently large $\lambda$ such that the first innovator applies for patent protection. When discoveries occur almost simultaneously, that is, $\lambda \rightarrow \infty$, patenting is the dominant strategy.

Finally, I examine how the degree of market competition affects the incentives to patent and the timing of patenting.

Proposition 5 There exists a $\tilde{j}$ such that as $n$ increases, innovator $j$ 's incentive to patent is higher (lower) if $j<\tilde{j}(j>\tilde{j})$. Consequently, there exists an $\tilde{\alpha}$ such that as $n$ increases, patenting occurs earlier (later) if $\alpha>\tilde{\alpha}(\alpha<\tilde{\alpha})$.

The key to understanding Proposition 5 is that an increase in the number of firms affects the profits arising from both patenting and secrecy. On the one hand, the profit from patenting decreases because more firms produce in the output market if patent protection is ineffective. This is the free ride effect. Note that the magnitude of this effect is the same for early and late innovators. On the other hand, an increase in the number of firms also decreases the profit from secrecy because the next discovery occurs sooner. This is the racing effect. However, compared to late innovators, early innovators are affected more significantly, as they face more potential competitors racing for discoveries. In other words, the racing effect is more prominent for early innovators. As shown in Figure 2, the incentives for early (late) innovators to patent increase (decrease) as $\alpha_{j}$ becomes lower (higher). 


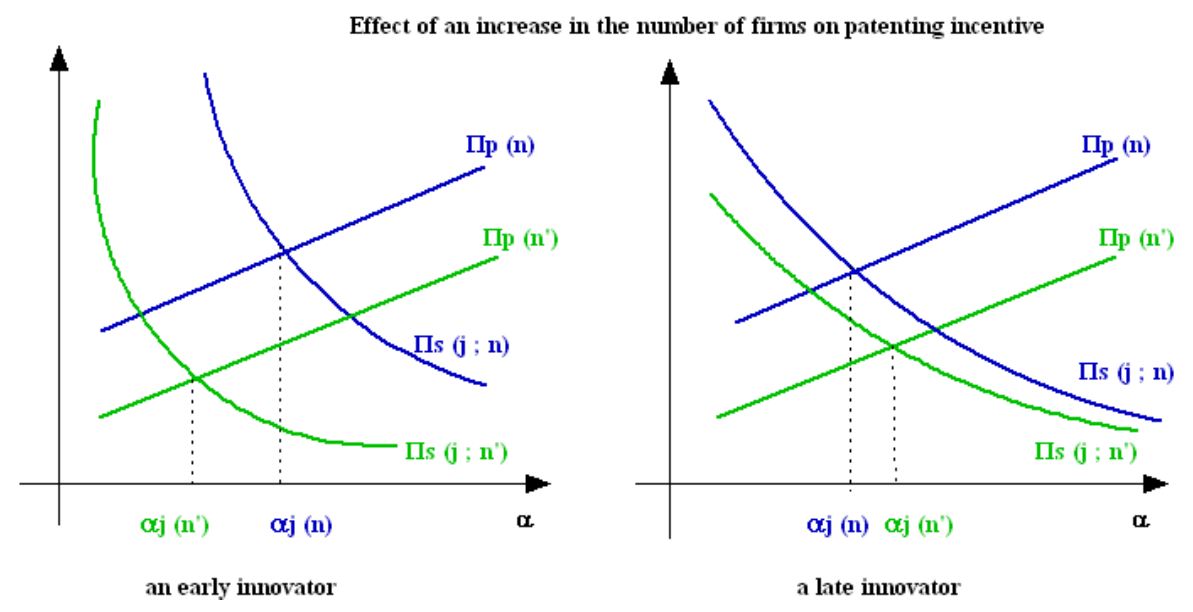

Figure 2

An increase in the number of firms may cause patenting to occur earlier or later, depending on the strength of patent protection. When patent protection is strong, an early innovator patents in equilibrium. As a greater number of firms strengthens the patenting incentive of the early innovator, patenting occurs earlier. When patent protection is weak, a late innovator patents in equilibrium. In this case, an increase in the number of firms weakens the late innovator's incentive to patent, which causes patenting to occur later. One important implication of Proposition 5 is that an increase in competition does not necessarily promote innovation information disclosure.

\section{Socially Optimal Patent Protection}

When an innovator considers its patenting and secrecy options, it does not internalize the effects on consumer surplus and the profits of its rivals. This section addresses the following question: given firms' patenting strategies, what is the optimal level of patent protection that maximizes social welfare?

There are two distinct perspectives on the function of patents. The first considers patents to be rewards for innovators. Without patent protection, innovations can be easily imitated. Thus, firms may be unable to reap sufficient profits to cover the costs associated with an innovation. Knowing this, firms may simply not to invest. As a result, innovation will not occur. In this view, the main goal of patents is to provide sufficient ex-ante innovation incentives.

This paper focuses on the second perspective regarding the function of patents. Following Denicolò and Franzoni (2004b), a patent is viewed as a contract or agreement between society 
and an innovator whereby the former affords the latter an exclusive right in exchange for innovation information disclosure. In this view, the main function of patents is to induce information disclosure after innovations occur. In the model adopted here, innovations follow a random process with an exogenous arrival rate. This structure allows us to abstract from the role of patents in providing an ex-ante innovation incentive and to focus on their function of inducing innovation information disclosure. ${ }^{13}$

Let $S_{k}$ be the instantaneous social welfare when $k$ firms produce in the output market. ${ }^{14}$ Assume that $S_{k}$ strictly increases with $k$. Suppose that, given $\alpha$, innovator $m$ patents in equilibrium. Define total social welfare, $T S(\alpha)$, as the sum of discounted instantaneous social welfare:

$$
\begin{aligned}
T S(\alpha)= & \frac{1}{r} \theta_{n-1} S_{1} \\
& +\frac{1}{r} \theta_{n-2}\left(1-\theta_{n-1}\right) S_{2} \\
& +\cdots \\
& +\frac{1}{r} \theta_{n-m+1}\left(1-\theta_{n-m+2}\right) \cdots\left(1-\theta_{n-1}\right) S_{m-1} \\
& +\frac{1}{r}\left(1-\theta_{n-m+1}\right)\left(1-\theta_{n-m+2}\right) \cdots\left(1-\theta_{n-1}\right)\left[\alpha S_{1}+(1-\alpha) S_{n}\right],
\end{aligned}
$$

where $\theta_{n-j}=\frac{r}{r+(n-j) \lambda}$. The first $m-1$ lines are the discounted social welfare in the first $m-1$ periods when early innovators opt for secrecy, and the last line is the discounted social welfare when innovator $m$ patents. A social planner's objective function is

$$
\max _{\alpha \in[0,1]} T S(\alpha)
$$

The next proposition states that the socially optimal level of patent protection induces the first innovator to patent.

Proposition 6 The socially optimal level of patent protection $\alpha^{*}$ is such that it is only sufficient to induce the first innovator to patent. That is, $\alpha^{*}=\alpha_{1}$.

The optimal level of patent protection involves a trade-off. On the one hand, innovation information disclosure benefits society because, with some degree of probability, other firms may utilize the innovation, which leads to a more competitive output market and thus

\footnotetext{
${ }^{13}$ It should be noted that the function of patents to provide an ex-ante innovation incentive is equally important, and an extensive body of literature is devoted to exploring the design of patent systems that reward innovators and encourage R\&D effort.

${ }^{14}$ The instantaneous social welfare is the sum of consumer and producer surplus.
} 
boosts social welfare. On the other hand, an innovator will not disclose information unless it receives sufficient compensation, which implies that sufficiently strong patent protection must be granted to trigger information disclosure. However, stronger patent protection is associated with a greater chance of a monopoly, which diminishes social welfare. Under the model setup in this paper, the welfare gain from early innovation information disclosure outweighs the welfare loss resulting from a potential monopoly. In addition, as long as the patent protection is sufficiently strong to induce the first innovator to patent, a further increase in patent protection merely increases the chance of a monopoly and, thus, reduces social welfare.

By definition, $\theta_{1}=\frac{r}{r+\lambda}<1$. Hence, from (6), $\alpha_{1}<1$. Corollary 1 follows.

Corollary 1 Full patent protection $(\alpha=1)$ is never socially optimal when $n>1$.

A monopoly firm demands full patent protection in exchange for revealing innovation information because it faces no potential threat. The situation changes in an oligopoly market. If the first innovator opts for secrecy, it could potentially be excluded by a later innovator that obtains a patent with effective protection. Thus, the level of patent protection that induces the first innovator to disclose information is lower than full protection.

Finally, by (6) and (3), it is straightforward to show the following proposition.

Proposition $7 \alpha^{*}$ decreases, respectively, with $\lambda$ and $n$.

Proposition 7 implies that the optimal level of patent protection varies with the nature of an innovation and the degree of competition in an industry. More specifically, the optimal level of patent protection is lower if the innovation arrival rate is higher or the number of firms is larger. For a higher innovation arrival rate or a larger number of firms, by Propositions 4 and 5, the first innovator receives less profit from secrecy and thus demands a lower level of patent protection in exchange for the disclosure of innovation information.

\section{Endogenous Innovation Arrival Rate}

In this section, I consider a simple model extension that incorporates an endogenous innovation arrival rate. I employ the framework in Loury (1979) and assume that firms incur an up-front R\&D investment that generates a steady flow of innovation arrivals over time. The extended model involves two stages. In stage 1, each firm chooses an R\&D investment level, $c\left(\lambda^{i}\right)$, which yields innovation arrival rate $\lambda^{i}$. Assume that $c\left(\lambda^{i}\right)$ is increasing and strictly convex in $\lambda^{i}$. In stage 2 , firms innovate stochastically and sequentially, and each firm 
decides whether to apply for patent protection. As firms are ex-ante identical, I consider the symmetric equilibrium in which each firm chooses the same level of R\&D investment, denoted as $c\left(\lambda^{*}\right)$, in the first stage.

Note that the second stage in the extended model is identical to the basic model in Section 2 except that the innovation arrival rate, $\lambda^{*}$, is endogenously determined by the R\&D investment, which is chosen by firms in the first stage. Therefore, by the principle of backward induction, the analysis of firms' decisions to patent remains valid after the innovation arrival rate is determined. More specifically, in the second stage, firms that innovate early are more inclined to choose secrecy, whereas those that innovate late have a stronger tendency to patent. Consequently, in equilibrium, early innovators adopt secrecy and only a sufficiently late innovator chooses to patent. Moreover, as firms make identical investments in the symmetric equilibrium, their expected profits decrease with the order of discoveries. Furthermore, an increase in patent protection bolsters firms' tendency to patent and causes patenting to occur earlier.

I next explore firms' $\mathrm{R} \& \mathrm{D}$ decisions in stage 1 . Let $V_{W}^{i}\left(V_{L}^{i}\right)$ be the present value of future profits from succeeding (not succeeding) in the $i t h$ period of stage $2 .{ }^{15}$ Suppose that innovator $m$ chooses to patent whereas previous innovators adopt secrecy in equilibrium. Given that other firms choose $\lambda^{*}$, a firm chooses $\lambda$ to maximize: ${ }^{16}$

$$
\begin{aligned}
V(\lambda) & =\int_{0}^{\infty} e^{-\left[\lambda+(n-1) \lambda^{*}\right] t}\left[\lambda V_{W}^{1}+(n-1) \lambda^{*} V_{L}^{1}(\lambda)\right] e^{-r t} d t-c(\lambda) \\
& =\frac{\lambda V_{W}^{1}+(n-1) \lambda^{*} V_{L}^{1}(\lambda)}{r+\lambda+(n-1) \lambda^{*}}-c(\lambda)
\end{aligned}
$$

where

$$
\begin{array}{rlrl}
V_{L}^{i} & =\frac{\lambda V_{W}^{i+1}+(n-i-1) \lambda^{*} V_{L}^{i+1}}{r+\lambda+(n-i-1) \lambda^{*}} & & \\
V_{L}^{m} & =\frac{1}{r}(1-\alpha) \pi_{n} & i=1, \ldots, m-1 \\
V_{W}^{i} & =\Pi_{s}(i \mid m) & \\
V_{W}^{m} & =\Pi_{p} . &
\end{array}
$$

To better understand these expressions, consider the expected payoff for a firm that enters in the $i+1$ th period. With a successful innovation, which occurs with instantaneous prob-

\footnotetext{
${ }^{15}$ Recall that stage 2 consists of $n$ periods and that period $j$ begins when firm $j$ innovates and ends when firm $j+1$ innovates.

${ }^{16}$ Note that there is a one-to-one correspondence between $\mathrm{R} \& \mathrm{D}$ investment $\operatorname{cost} c\left(\lambda^{i}\right)$ and innovation arrival rate $\lambda^{i}$. For convenience, $\lambda^{i}$ is selected as the choice variable.
} 
ability $\frac{\lambda}{r+\lambda+(n-i-1) \lambda^{*}}$, the firm receives $V_{W}^{i+1}$. If one of its rivals innovates, which occurs with instantaneous probability $\frac{(n-i-1) \lambda^{*}}{r+\lambda+(n-i-1) \lambda^{*}}$, then the payoff to the firm is $V_{L}^{i}(\lambda)$.

First-order conditions, allowing $\lambda=\lambda^{*}$, yield

$$
\frac{r V_{W}^{1}+(n-1) \lambda^{*}\left[V_{W}^{1}-V_{L}^{1}\left(\lambda^{*}\right)+\left(r+n \lambda^{*}\right) \frac{\partial V_{L}^{1}\left(\lambda^{*}\right)}{\partial \lambda}\right]}{\left(r+n \lambda^{*}\right)^{2}}-c^{\prime}\left(\lambda^{*}\right)=0
$$

and

$$
\frac{\partial V_{L}^{i}\left(\lambda^{*}\right)}{\partial \lambda}=\frac{r V_{W}^{i+1}+(n-i-1) \lambda^{*}\left\{V_{W}^{i+1}-V_{L}^{i+1}\left(\lambda^{*}\right)+\left[r+(n-i) \lambda^{*}\right] \frac{\partial V_{L}^{i+1}\left(\lambda^{*}\right)}{\partial \lambda}\right\}}{\left[r+(n-i) \lambda^{*}\right]^{2}} .
$$

The equilibrium $\lambda^{*}$ is implicitly defined by (14) and (15). ${ }^{17}$

How does the incentive to innovate respond to stronger patent protection? In general, stronger patent protection provides greater rewards to innovators and thus increases the incentive to innovate. This conventional wisdom continues to hold in the model if the initial patent protection is sufficiently strong. However, in this paper's model setting, R\&D investment is generally not monotone in the strength of patent protection, although I am unable to show this analytically. To illustrate, consider a simple case of two firms. If the initial patent protection is strong, then a higher $\alpha$ induces a higher $\lambda^{*}$. The reasoning is straightforward: stronger patent protection provides greater potential rewards for the first successful innovator to patent an innovation. Thus, the firms in the patent race have a greater incentive to innovate. Interestingly, if patent protection is initially weak, then an increase in $\alpha$ may lead to a lower $\lambda^{*}$. To see this, note that if the initial patent protection is weak, then, in equilibrium, the first innovator adopts secrecy and the second innovator chooses to patent. A marginal increase in patent protection, as long as it does not induce the first innovator to patent, has no effect on the payoff to the first innovator. However, it does increase that to the second innovator. In other words, the payoff difference between the first and second innovator becomes smaller, which weakens the incentive to invest in R\&D in the first stage. ${ }^{18}$

\footnotetext{
${ }^{17}$ Consistent with the previous literature on patent races, the overall R\&D investment is excessive compared to the cooperative equilibrium. The economic intuition underlying this result is that each firm ignores its impact on its rivals' payoffs, and, consequently, there is too much duplication of effort in the noncooperative equilibrium.

${ }^{18}$ Suppose that $n=2$ and output market competition is Bertrand fashion, which implies $\pi_{2}=0$. Moreover, assume that $r=0.2, \pi_{1}=1$, and $c(\lambda)=\lambda^{2}$. By (6), $\alpha_{1}=0.31$. Thus, in equilibrium, firm 1 patents if $\alpha>\alpha_{1}$. Substituting (15) into (14), the first-order condition becomes $\alpha\left(r+\lambda^{*}\right)-2 r \lambda^{*}\left(r+2 \lambda^{*}\right)^{2}=0$. If $\alpha \leq \alpha_{1}$, then firm 1 adopts secrecy, and firm 2 patents. The first-order condition becomes $-\alpha \lambda^{* 3}+r(1+\alpha) \bar{\lambda}^{* 2}+$
} 


\section{Conclusion}

The heterogeneity of the choices to patent or to maintain secrecy are well documented. I have shown how these choices may arise as a market equilibrium in a legal environment characterized by imperfect patent protection and no prior user rights. I have also shown how innovators' incentives to patent depend on the nature of innovation and the degree of market competition. A focus on the function of patents to induce innovation information disclosure reveals that the optimal level of patent protection is lower when the innovation arrival rate is higher or the number of firms is larger.

For future research, it would be interesting to examine how firms' patenting decisions depend on the nature of innovations and the degree of market competition in a framework of cumulative innovation. ${ }^{19}$ It would also be interesting to extend the model to a vertical industry structure and ascertain how the presence of vertical integration affects an upstream firm's incentive to patent. ${ }^{20}$

\section{Appendix}

\section{Proof of Lemma 2}

Proof. As the model assumes complete information, an innovator correctly anticipates the strategies of subsequent innovators. Suppose it is expected that innovator $h(h>j+1)$ will apply for patent protection at time $T_{h}$ when it discovers the technology. In addition, denote $\Xi\left(s_{j}\right)$ as the profit distribution for innovator $j$ up to time $s_{j}$ and $\Xi\left(s_{j+1}\right)$ as the profit distribution for innovator $j+1$ up to time $s_{j+1}$. Note that at each point in time $s_{j}=s_{j+1}$, and $\Xi\left(s_{j}\right)$ first-order stochastically dominates $\Xi\left(s_{j+1}\right)$. Thus, the expected profit that arises

from secrecy protection for innovator $j, \Pi_{s}(j \mid h)=\int_{0}^{T_{h}} \Xi\left(s_{j}\right)+\int_{0}^{T_{h}}(1-\alpha) \pi_{n}$, is higher than that for innovator $j+1, \Pi_{s}(j \mid h)=\int_{0}^{T_{h}} \Xi\left(s_{j+1}\right)+\int_{0}^{T_{h}}(1-\alpha) \pi_{n}$. Given that innovator $j+1$ optimally chooses secrecy, it follows that $\Pi_{s}(j+1 \mid h)>\Pi_{p}$. Hence, $\Pi_{s}(j \mid h)>\Pi_{p}$. That is, innovator $j$ opts for secrecy.

\section{Proof of Proposition 1}

Proof. By (8), $\left\{\alpha_{j}\right\}_{j \in N}$ is a strictly decreasing sequence. Moreover, by $(6), \alpha_{N}=0$. Thus, $[0,1]$ is divided into non-overlapping intervals. For any given $\alpha \in[0,1]$, a unique $m \in N$

$\overline{r^{2}(2+\alpha) \lambda^{*}+r^{3}-2 r \lambda^{*}\left(r+\lambda^{*}\right)^{2}\left(r+2 \lambda^{*}\right)^{2}}=0$. Numerical analysis suggests that if $\alpha \geq 0.31$, then a higher $\alpha$ induces a higher $\lambda^{*}$; if $\alpha<0.31$, then a higher $\alpha$ leads to a lower $\lambda^{*}$.

${ }^{19}$ See Green and Scotchmer (1995) and Erkal (2005) for models of cumulative innovation.

${ }^{20}$ See Chen and Sappington (2010) for recent work on innovation in vertically related markets. 
exists such that $\alpha_{m}<\alpha \leq \alpha_{m-1}$.

To show the second half of the proposition, I use backward induction by considering the choice of the last innovator (innovator $n$ ). When comparing the profit from patenting strategy, $\Pi_{p}$, to that from secrecy strategy, $\Pi_{s}(n)$, it can be shown that $\Pi_{s}(n)=\frac{1}{r} \pi_{n}<$ $\frac{1}{r}\left[\alpha \pi_{1}+(1-\alpha) \pi_{n}\right]=\Pi_{p}$. That is, the last innovator will choose to apply for patent protection. This is because secrecy provides no extra benefits because all of the other firms have already discovered the technology. Given that innovator $n$ will apply for patent protection, I now consider the choice of innovator $n-1$. If $m=n$, then $\alpha<\alpha_{n-1}$, which implies that innovator $n-1$ will choose secrecy. By Lemma 2, innovator $j(j<m)$, if any, opts for secrecy. If $m<n$, then $\alpha>\alpha_{n-1}$. Thus, innovator $n-1$ chooses to apply for patent protection. As $\left\{\alpha_{j}\right\}$ is strictly decreasing with $j$, it can be shown that, for $\alpha>\alpha_{m}$, innovator $j(j \geq m)$ chooses to apply for patent protection. In addition, as $\alpha \leq \alpha_{m-1}$, it follows that innovator $m-1$ chooses secrecy over patenting. By Lemma 2, it is straightforward to show that innovator $j$ $(j<m)$ opts for secrecy.

\section{Proof of Proposition 2}

Proof. Suppose that innovator $m$ applies for patent protection. By Proposition 1, innovator $i(i<m)$ opts for secrecy. By Lemma $2, \Pi_{s}(j \mid m)>\Pi_{s}(j+1 \mid m)$. Hence, the expected profits decrease with $j$ when $j<m$. In addition, the expected profit for innovator $m$ is $\Pi_{p}$. Furthermore, innovator $m-1$ opts for secrecy, which implies $\Pi_{s}(m-1)>\Pi_{p}$. Finally, the profit for innovator $j(j>m)$ is

$$
\frac{1}{r}(1-\alpha) \pi_{n}<\frac{1}{r}\left[\alpha \pi_{1}+(1-\alpha) \pi_{n}\right]=\Pi_{p} .
$$

This completes the proof.

\section{Proof of Proposition 3}

Proof. Suppose that $\hat{\alpha}>\alpha$. Define $\hat{m}=m(\hat{\alpha}, \lambda, n)$ and $m=m(\alpha, \lambda, n)$. In equilibrium, we have $\alpha_{m}<\alpha \leq \alpha_{m-1}$. It follows that $\alpha_{m} \leq \hat{\alpha}$. As a change in $\alpha$ has no effect on $\alpha_{j}$, and since $\hat{\alpha} \in\left(\alpha_{\hat{m}}, \alpha_{\hat{m}-1}\right]$, we have $\alpha_{m} \leq \alpha_{\hat{m}}$. By (8), $\hat{m} \leq m$. Moreover, define $\hat{\rho}=\rho(\hat{\alpha}, \lambda, n)$ and $\rho=\rho(\alpha, \lambda, n)$. By (9), $\hat{\rho} \leq \rho$. Furthermore, let $\hat{T}=T(\hat{\alpha}, \lambda, n)$ and $T=T(\alpha, \lambda, n)$. By (10), we have $\hat{T} \leq T$.

\section{Proof of Proposition 4}

Proof. From equation (6), $\alpha_{j}$ increases in $\theta_{n-j}$. Therefore, $\alpha_{j}$ decreases in $\lambda$, as $\theta_{n-j}$ 
decreases in $\lambda$. Hence, if $\hat{\lambda}>\lambda$, then $\alpha_{j}(\hat{\lambda})<\alpha_{j}(\lambda)$. For any given $\lambda$, we have $\alpha_{m}(\lambda)<\alpha \leq$ $\alpha_{m-1}(\lambda)$. It follows that $\alpha>\alpha_{m}(\hat{\lambda})$. Therefore, for any given $\hat{\lambda}, m(\alpha, \hat{\lambda}, n) \leq m(\alpha, \lambda, n)$. It follows that $\rho(\hat{\alpha}, \lambda, n) \leq \rho(\alpha, \lambda, n)$ by $(9)$ and $T(\alpha, \hat{\lambda}, n) \leq T(\alpha, \lambda, n)$ by $(10)$.

\section{Proof of Proposition 5}

Proof. Step 1: I show that for any given $\alpha_{j}$, there exists a cutoff value,

$$
\lambda_{j}=\frac{r\left(\pi_{1}-\pi_{j}\right)\left(\pi_{n}-\pi_{n+1}\right)}{\pi_{1}\left[\pi_{j}-\pi_{n}-(n-j)\left(\pi_{n}-\pi_{n+1}\right)\right]},
$$

such that $\alpha_{j}$ increases with $n$ if $\lambda<\lambda_{j}$, but decreases with $n$ if $\lambda>\lambda_{j}$.

To see this, take the difference between $\alpha_{j}(n)$ and $\alpha_{j}(n+1)$. Note that $x(j)=1-\theta_{n-j}$. By (6),

$$
\alpha_{j}(n)-\alpha_{j}(n+1)=\frac{\left(\pi_{j}-\pi_{n}\right)\left(\frac{\pi_{1}}{\theta_{n+1-j}}-\pi_{n+1}\right)-\left(\pi_{j}-\pi_{n+1}\right)\left(\frac{\pi_{1}}{\theta_{n-j}}-\pi_{n}\right)}{\left(\frac{\pi_{1}}{\theta_{n-j}}-\pi_{n}\right)\left(\frac{\pi_{1}}{\theta_{n+1-j}}-\pi_{n+1}\right)} .
$$

Clearly, the denominator on the right-hand side of the equation is positive because $\theta_{n-j}<1$. Substituting $\theta_{n-j}$ into the numerator on the right-hand side and rearranging terms, we have $\operatorname{sign}\left[\alpha_{j}(n)-\alpha_{j}(n+1)\right]=\operatorname{sign}\left[\left(\pi_{j}-\pi_{n}\right)-(n-j)\left(\pi_{n}-\pi_{n+1}\right)\right] \frac{\pi_{1}}{r} \lambda-\left(\pi_{1}-\pi_{j}\right)\left(\pi_{n}-\pi_{n+1}\right)$.

Define $\lambda_{j}$ as in (16). If $\lambda>\lambda_{j}$, then $\left[\left(\pi_{j}-\pi_{n}\right)-(n-j)\left(\pi_{n}-\pi_{n+1}\right)\right] \frac{\pi_{1}}{r} \lambda-\left(\pi_{1}-\pi_{j}\right)\left(\pi_{n}-\pi_{n+1}\right)>$ 0 , which implies $\alpha_{j}(n)>\alpha_{j}(n+1)$. If $\lambda<\lambda_{j}$, then $\left[\left(\pi_{j}-\pi_{n}\right)-(n-j)\left(\pi_{n}-\pi_{n+1}\right)\right] \frac{\pi_{1}}{r} \lambda-$ $\left(\pi_{1}-\pi_{j}\right)\left(\pi_{n}-\pi_{n+1}\right)<0$, which implies $\alpha_{j}(n)<\alpha_{j}(n+1)$.

Step 2: I show that $\lambda_{j}$ increases with $j$.

It is straightforward to show that $\lambda_{1}=0$. To see that $\left\{\lambda_{j}\right\}$ increases in $j$, note that

$$
\begin{gathered}
\quad \lambda_{j}-\lambda_{j+1}=\frac{r\left(\pi_{1}-\pi_{j}\right)\left(\pi_{n}-\pi_{n+1}\right)}{\pi_{1}\left[\pi_{j}-\pi_{n}-(n-j)\left(\pi_{n}-\pi_{n+1}\right)\right]}-\frac{r\left(\pi_{1}-\pi_{j+1}\right)\left(\pi_{n}-\pi_{n+1}\right)}{\pi_{1}\left[\pi_{j+1}-\pi_{n}-(n-j-1)\left(\pi_{n}-\pi_{n+1}\right)\right]} \\
=\zeta \cdot\left\{\left(\pi_{1}-\pi_{j}\right)\left[\pi_{j+1}-\pi_{n}-(n-j-1)\left(\pi_{n}-\pi_{n+1}\right)\right]-\left(\pi_{1}-\pi_{j+1}\right)\left[\pi_{j}-\pi_{n}-(n-j)\left(\pi_{n}-\pi_{n+1}\right)\right]\right\},
\end{gathered}
$$

where $\zeta=\frac{r\left(\pi_{n}-\pi_{n+1}\right)}{\pi_{1}\left[\pi_{j}-\pi_{n}-(n-j)\left(\pi_{n}-\pi_{n+1}\right)\right]\left[\pi_{j+1}-\pi_{n}-(n-j-1)\left(\pi_{n}-\pi_{n+1}\right)\right]}>0$. Thus,

$$
\begin{aligned}
& \operatorname{sign}\left(\lambda_{j}-\lambda_{j+1}\right) \\
= & \operatorname{sign}\left\{-\left(\pi_{1}-\pi_{j}\right)\left[\pi_{j}-\pi_{j+1}-\left(\pi_{n}-\pi_{n+1}\right)\right]-\left(\pi_{j}-\pi_{j+1}\right)\left[\left(\pi_{j}-\pi_{n}\right)-(n-j)\left(\pi_{n}-\pi_{n+1}\right)\right]\right\} .
\end{aligned}
$$

However, $\pi_{j}-\pi_{n}-\left(\pi_{j+1}-\pi_{n+1}\right)=\pi_{j}-\pi_{j+1}-\left(\pi_{n}-\pi_{n+1}\right)>0$ and $\left(\pi_{j}-\pi_{n}\right)=\pi_{j}-$ 
$\pi_{j+1}+\pi_{j+1}-\pi_{j+2}+\cdots+\pi_{n-1}-\pi_{n}>(n-j)\left(\pi_{n-1}-\pi_{n}\right)>(n-j)\left(\pi_{n}-\pi_{n+1}\right)$. Therefore, sign $\left(\lambda_{j}-\lambda_{j+1}\right)<0$. That is, $\left\{\lambda_{j}\right\}$ increases with $j$.

Step 3: For any given $\lambda$, as $n$ increases, there exists a $k(\lambda)$, such that $\alpha_{j}(n)>\alpha_{j}(n+1)$ for $j<k$ and $\alpha_{j}(n)<\alpha_{j}(n+1)$ for $j \geq k$. Define $\tilde{\alpha}=\alpha_{k}(n+1)$. If $\alpha>\tilde{\alpha}$, then $m(n) \geq m(n+1)$, which implies $T(n) \geq T(n+1)$. If $\alpha<\tilde{\alpha}$, then $m(n)<m(n+1)$, which implies $T(n)<T(n+1)$.

\section{Proof of Proposition 6}

Proof. First, I show that total social welfare can be increased if a reduction in $\alpha$ results in the same $m$ in equilibrium. Suppose that $\hat{\alpha}>\alpha$, but they lead to the same equilibrium $m$. By (11),

$$
\begin{aligned}
T S(\alpha)-T S(\hat{\alpha})= & \frac{1}{r}\left(1-\theta_{n-m+1}\right)\left(1-\theta_{n-m+2}\right) \cdots\left(1-\theta_{n-1}\right)\left[\alpha S_{1}+(1-\alpha) S_{n}\right] \\
& -\frac{1}{r}\left(1-\theta_{n-m+1}\right)\left(1-\theta_{n-m+2}\right) \cdots\left(1-\theta_{n-1}\right)\left[\hat{\alpha} S_{1}+(1-\hat{\alpha}) S_{n}\right] \\
= & \frac{1}{r}\left(1-\theta_{n-m+1}\right)\left(1-\theta_{n-m+2}\right) \cdots\left(1-\theta_{n-1}\right)(\alpha-\hat{\alpha})\left(S_{1}-S_{n}\right)>0 .
\end{aligned}
$$

Therefore, total social welfare can be increased by reducing $\hat{\alpha}$ to $\alpha$.

Second, by the above result, the set of possible $\alpha$ leading to total social welfare maximization can be greatly reduced. More specifically, total social welfare maximization occurs when $\alpha$ is only sufficient to induce a switch in $m$. In other words, the optimal level of patent protection occurs at one of the $\left\{\alpha_{j}\right\}_{j \in N}$. Hence, it is necessary only to compare $n$ possible equilibrium outcomes. The social planner's problem is simplified to

$$
\max _{\alpha \in \Omega(\alpha)} T S(\alpha) \quad \text { where } \quad \Omega(\alpha)=\left\{\alpha_{j}, j \in N\right\}
$$

The social planner chooses an $\alpha_{j}$ to maximize total social welfare. However, each $\alpha_{j}$ is uniquely associated with an $m$. Therefore, it is as though the social planner chooses $m$ to maximize total social welfare.

Third, from Proposition 1, innovator 1 applies for patent protection if $\alpha>\alpha_{1}$. We have

$$
T S\left(\alpha_{1}\right)=\frac{1}{r}\left[\alpha_{1} S_{1}+\left(1-\alpha_{1}\right) S_{n}\right]
$$

Next, consider $\alpha=\alpha_{j}$ for any given $j>1$. Note that $S_{1}<S_{2}<\cdots<S_{n}$. Hence, 
$\alpha S_{1}+(1-\alpha) S_{n}<S_{n}$. We have

$$
\begin{aligned}
T S\left(\alpha_{j}\right)< & \frac{1}{r} \theta_{n-1} S_{1}+\frac{1}{r} \theta_{n-2}\left(1-\theta_{n-1}\right) S_{n}+\ldots+\frac{1}{r} \theta_{n-m+1}\left(1-\theta_{n-m+2}\right) \cdots\left(1-\theta_{n-1}\right) S_{n} \\
& +\frac{1}{r}\left(1-\theta_{n-m+1}\right)\left(1-\theta_{n-m+2}\right) \cdots\left(1-\theta_{n-1}\right) S_{n} \\
= & \frac{1}{r}\left[\theta_{n-1} S_{1}+\left(1-\theta_{n-1}\right) S_{n}\right] .
\end{aligned}
$$

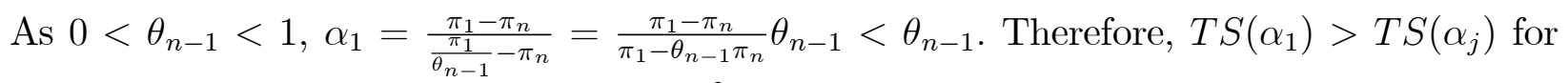
any given $j>1$. This completes the proof.

\section{References}

[1] Allison, J. and Lemley, M., "Empirical analysis of the validity of litigated patents", American Intellectual Property Law Association Quarterly Journal, 26(3):185-275, (1998).

[2] Anton, J. and Yao, D., "Little patents and big secrets: managing intellectual property", RAND Journal of Economics, 35, 1-22, (2004).

[3] Chen, Y. and Sappington, D., "Innovation in vertically related markets", Journal of Industrial Economics, 58, 373-401 (2010).

[4] Choi, J., "Market structure, incentive to patent and the pace of innovation", Economics Letters, 34, 277-283, (1990).

[5] Choi, J., "Patenting litigation as an information transmission mechanism", American Economic Review, 88, 1249-1263. (1998).

[6] Cohen, W., Nelson, R., and Walsh, J., "Protecting their intellectual assets: appropriability conditions and why U.S. manufacturing firms patent (or not)", NBER working paper W7552. (2000).

[7] Denicolò, V. and Franzoni, L., "Patenting, secrets, and the first-inventor defense", Journal of Economics and Management Strategy, 13, 517-538, (2004).

[8] Denicolò, V. and Franzoni, L., "The contract theory of patents", International Review of Law and Economics, 23, 365-380, (2004).

[9] Denicolò, V. and Franzoni, L., "On the winner-take-all principle in innovation races", Journal of the European Economic Association, 8(5), 1133-1158, (2010). 
[10] Erkal, N., "The decision to patent, cumulative innovation, and optimal policy" International Journal of Industrial Organization, 23, 535-562, (2005).

[11] Erkal, N. and Scotchmer, S., "Scarcity of ideas and R\&D options: use it, lose it or bank it", NBER Working Paper No. 14940. (2009).

[12] Gallini, T., "Patent policy and costly imitation", RAND Journal of Economics, 23 (1):52-63, (1992).

[13] Green, J. and Scotchmer, S., "On the division of profit in sequential innovation", Rand Journal of Economics, 26, 20-33, (1995).

[14] Horstmann, I., MacDonald, G., and Slivinski, A., "Patents as information transfer mechanisms: to patent or (maybe) not to patent", Journal of Political Economy, Vol, 93. 837-58. (1985).

[15] Kultti, K., Takalo, T., and Toikka, J., "Simultaneous model of innovation, secrecy, and patent policy", American Economic Review, 96, 82-86 (2006).

[16] Kultti, K., Takalo, T., and Toikka, J., "Secrecy versus patenting", RAND Journal of Economics, 38, 22-42.(2007).

[17] La Manna, M., MacLeod, R., and de Meza, D., "The case for permissive patents", European Economic Review, 33, 1427-1443 (1989).

[18] Lemley, M. and Shapiro, C., "Probabilistic patents", Journal of Economic Perspectives, 19, 75-98.(2005).

[19] Levin, R., Klevorick, R., Nelson, R., and Winter, S., "Appropriating the returns from industrial research and development", Brookings Papers on Economic Activity, 3, 783820.(1987).

[20] Loury, G., "Market structure and innovation", Quarterly Journal of Economics, 93, 395-410 (1979).

[21] Marshall, E., "The patent game: raising the ante", Science 253: 20-24 (1991).

[22] Mansfield, E., "Patents and innovation: An empirical study", Management Science, 32(2):173-181, (1986).

[23] Merges, R. and Duffy, J., Patent Law and Policy: Cases and Materials, LexisNexis, (2007). 
[24] Pakes, A. and Griliches, Z., "Patents and R\&D at the firm level: A first look", Economics Letters, 5, no 4, 377-81. (1980).

[25] Reinganum, J., "The timing of innovation: research, development, and diffusion", Handbook of Industrial Organization, Vol. 1, R. Schmalensee and R.D. Willig eds.(1989).

[26] Scherer, F., "Firm size, market structure, opportunity, and the output of patented inventions", American Economic Review, 55, 1097-1125. (1965).

[27] Scotchmer, S., Innovation and Incentives. The MIT Press, (2004).

[28] Shapiro, C., "Prior user rights", American Economics Review, 96, 92-96, (2006).

[29] Shapiro, C., "Patent reform: Aligning reward and contribution", NBER working papers, National Bureau of Economic Research, Inc, May (2007).

[30] Varian, H., Farrell, J. and Shapiro, C., The Economics of Information Technology: An Introduction. Cambridge University Press, (2005). 